\begin{tabular}{|c|c|}
\hline $\begin{array}{r}\text { GEOAMBIENTE ON-LINE } \\
\text { Revista Eletrônica do Curso de Geografia do Campus Jataí - UFG } \\
\text { www.jatai.ufg.br/geografia } \\
\mid \text { Jataí-GO | N.11 | jul-dez/2008 | }\end{array}$ & 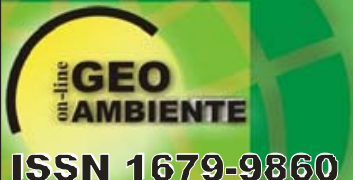 \\
\hline
\end{tabular}

\title{
O(S) SENTIDO(S) DE AMBIENTE NAS TRAMAS DO PENSAMENTO AMBIENTALISTA CONTEMPORÂNEO
}

\author{
ROSEMERI MELO E SOUZA ${ }^{1}$
}

(1 - Departamento de Geografia/UFS. Cidade Universitária "Prof. José Aloísio de Campos, Av. Marechal Rondon, S/N, Pólo de Pós-Graduação, sala 01. CEP: 49100-000 - São

Cristóvão, SE. Telefone: (79) 21056796 - Fax (79) 2105-6793.E-mails:

rosemeri.melo@pq.cnpq.brou rome@ufs.br)

\section{Resumo}

Este ensaio reporta-se a uma análise das matrizes interpretativas dos sentidos do ambiente dentro das possibilidades de novas ligações destes sentidos num contexto marcado pela fragmentação paradigmática e pela renúncia epistemológica aos grandes modelos explicativos da realidade, como eixos analíticos da contemporaneidade. Em primeiro lugar, a autora analisa a noção de contrato natural e suas contribuições ao conceito de ambiente.Depois, discute alguns sentidos de natureza dentro da questão ambiental, concluindo com a proposição teórica da adoção do conceito de Gaia como instaurador de novos sentidos interpretativos, negociados entre sujeitos do processo educativo, dentro de uma matriz hermenêutica, com ênfase no campo do pensamento ambientalista na contemporaneidade.

Palavras chave: Hermanêutica, Sentidos de Natureza, Ambientalismo, Questões Ambientais.

\section{Abstract \\ THE SENSES OF ENVIRONMENT IN THE PLOTS OF CONTEMPORARY ENVIRONMENTALIST THOUGHT}

This essay refers to an analysis of matrices interpretation of the meanings of the environment within the possibilities of new connections of these senses in a context marked by fragmentation paradigmatic and the resignation epistemological the major explanatory models of Indeed, as shafts of contemporary analytical. Firstly, the author examines the concept of

Recebido para publicação em 26 de Junho de 2008;

Aprovado para publicação em 12 de Setembro de 2008 


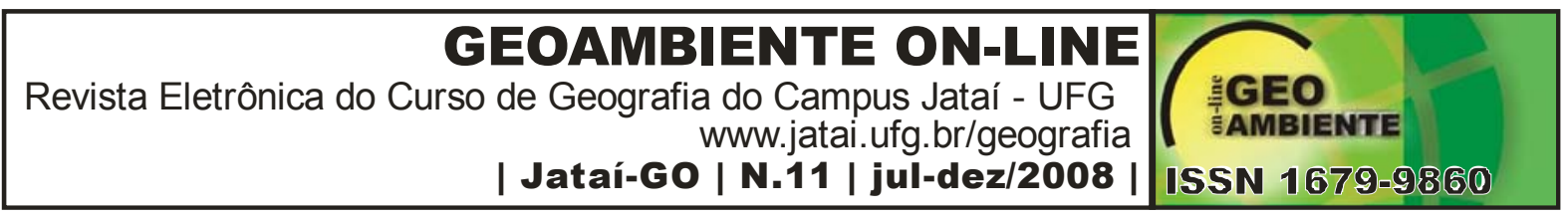

contract natural and their contributions to the concept of environment. Then, discusses some sense of nature within the environmental issue, concluding with the theoretical proposition of adopting the concept of Gaia as a foundation of new interpretative senses, negotiated between subjects in the educational process, within a hermeneutics matrix, with emphasis in the field of environmentalism in the contemporaneity.

Key Words: Hermeneutics, Sense of Nature, Environmentalism, Environmental Questions.

”A Terra existiu sem nossos inimagináveis antepassados, poderia muito bem existir hoje sem nós e existirá amanhã ou ainda mais tarde sem nenhum dos nosso possiveis descendentes, mas nós não podemos existir sem ela” Michel Serres

\section{I - Introdução}

Este artigo tem como propósito analisar os sentidos de ambiente construídos no cerne do pensamento ambientalista contemporâneo, tendo como proposição a referência a Gaia como uma possibilidade hermenêutica instauradora de novos sentidos no âmbito das vertentes do movimento ambientalista.

O ensaio consiste em uma discussão conceitual apoiada em teóricos cujas contribuições à constituição do campo do pensamento ambientalista proporcionou uma leitura analítica de suas contribuições na busca de uma perspectiva hermenêutica das possibilidades constitutivas de um discurso ambiental erigido à luz da concepção de que tudo está ligado.

O artigo traz a discussão em três momentos, a saber: o questionamento do conceito de ambiente à luz do contrato natural, conforme desenvolvido pelo filósofo Michel Serres.

O segundo momento reporta-se à análise das concepções de natureza, buscando problematizar os sentidos circulantes de meio ambiente e algumas possibilidades de ressignificação.

Por fim, o terceiro momento apresenta alguns desdobramentos interpretativos dos trânsitos epistêmicos do campo ambiental no Brasil.

Conclui-se com a proposição de Gaia como uma hermenêutica instauradora de novos sentidos de ambiente no pensamento ambientalista na contemporaneidade. 


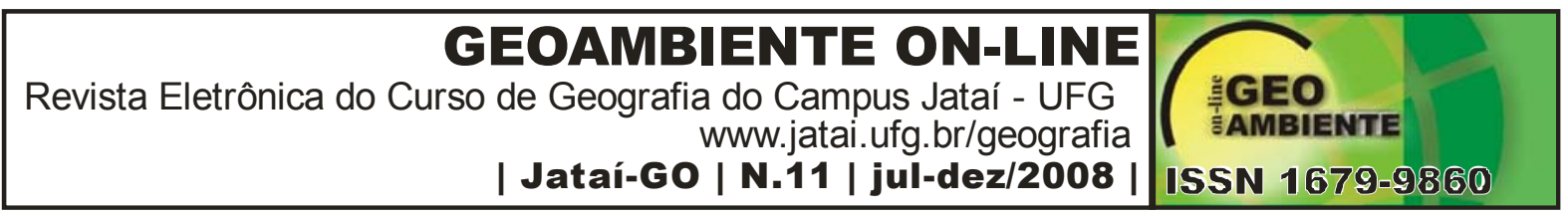

\section{II - Natureza e contrato natural: o conceito de ambiente em questão}

Pensar as matrizes interpretativas do ambiente implica assumir duas posturas demarcatórias dentro desse campo discursivo, a saber: a primeira que tal atitude implica uma necessária ressignificação do humanismo ocidental no campo discursivo acerca da questão ambiental; a segunda postura envolve uma ancoragem hermenêutica na qual não se busca uma explicação, mas sim uma compreensão dos trânsitos, ou seja, dos movimentos dialógicos e dos giros interpretativos entre pares irreconciliáveis dentro de uma visão cientificista e restritiva, tais como objetivo-subjetivo, local-global, sujeito-objeto, disciplinaridade do conhecimento- (multi)disciplinaridade ( FLORIANI, 2006).

Assim, assume-se, do ponto de vista da racionalidade hegemônica orientada por uma visão fragmentária da Vida que a natureza não pode formular concepções sobre si mesma como uma justificativa de nulificação deste debate, assertiva esta que pretendemos reinterpretar partindo de outro contexto, ou seja, da possibilidade de "acrescentar ao contrato exclusivamente social, a celebração de um contrato natural de reciprocidade entre nós e os demais seres do mundo em que o conhecimento já não suporia propriedade." ( SERRES, 1990, p. 65, grifos nossos).

Por conseguinte, estabelecer um debate entre os trânsitos dos sentidos de ambiente nas tramas da complexidade que comporta este campo discursivo implica, desde já, abdicarmos do sentido humanismo de cunho antropocêntrico que nos coloca a nós, homens e mulheres, no centro do universo, senhores e possuidores da natureza. Isto também implica abrirmos mão, para possibilitar esta celebração à qual alude Serres (1990), de assumirmos a nossa condição de criaturas coligadas e mais ainda - coexistentes - com os demais seres em um novo estatuto epistêmico e concreto, se não de igualdade, certamente de interdependência última para nossa sobrevida no planeta.

Ao abdicar-se deste sentido antropocêntrico embutido na origem semântica do termo ambiente, é preciso retomar ainda que de modo ligeiro, a gênese da formulação desta palavra, empregada pela primeira vez em 1869 pelo alemão Troll (apud SANTOS, 1992) não está nas referências), tal termo envolvia uma acepção de mundo natural modificado pela ação humana. Nas ciências sociais, aproximou-se, depois de quase dois séculos, das formulações de Marx acerca da primeira e segunda natureza formuladas em sincronia com a elaboração do conceito do naturalista germânico. 


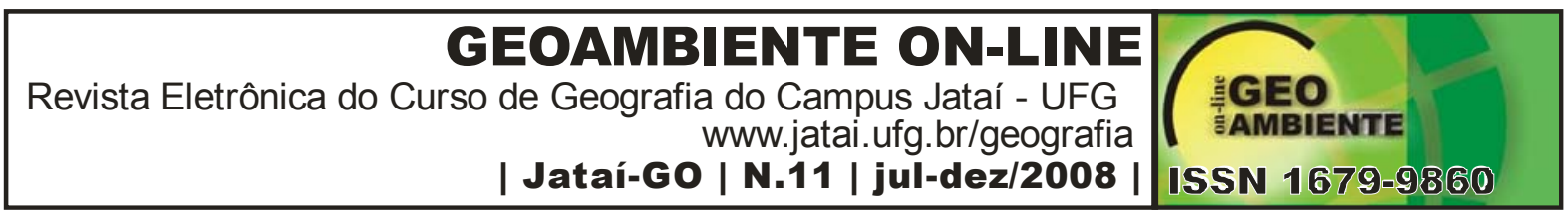

Por conseguinte, pensar o ambiente sempre envolveu um Logos (Discurso, Dizer, Saber, Razão) fundado em uma racionalidade dominadora do homem sobre as demais formas de vida, em que conhecer implicava, desde sempre, dominar, possuir.

Desvendar alguns sentidos interpretativos de ambiente nas tramas da complexidade contemporânea, recolocando a celebração de Serres (1990) como possibilidade no campo discursivo, também equivale a dizer que esta abordagem se instaura além do Logos de uma razão instrumentalizadora da natureza, buscando reconstruir novos sentidos e possibilidades de rearticulação de práticas dos sujeitos sociais rumo à emancipação do próprio processo educativo e de uma hermenêutica que insira a educação, em sua dimensão ambiental, enquanto novo eixo de articulação da problemática sociedade-natureza (CARVALHO, 2003).

\section{III - Problematizando a questão ambiental e alguns sentidos de natureza}

Embora a questão ambiental apresente-se como uma das temáticas mais importantes das últimas décadas, a análise do problema ambiental não assumiu, na mesma proporção, a evolução necessária: seja pela limitação imposta pelo horizonte positivista que perdura sobre a comunidade científica, seja pelo elitismo da classe intelectual, que limita a compreensão da essência do problema pela sociedade. Desta forma, para o entendimento do problema em sua totalidade, torna-se indispensável compreender algumas concepções de natureza.

Todavia, não se pretende aqui apenas uma "história" da evolução destas visões, mas perceber como estas alimentam os pensamentos sobre a questão ambiental e orientam a prática do sujeito em torno dessa temática.

Na pré-história quando a concepção de natureza estava atrelada a uma visão mágica, deificada, edênica, a relação desta com o homem foi no entendimento de Santos (1992), uma relação de "amizade".

Nos dizeres do próprio teórico, ontem, o homem escolhia em torno, naquele seu quinhão de natureza, o que lhe podia ser útil para a renovação de sua vida: espécies animais e vegetais, pedras, árvores, florestas, rios, feições geológicas. Esse pedaço de Mundo é, na Natureza toda de que ele pode dispor, seu sub-sistema útil, seu quadro vital. Então há descoordenação entre grupos humanos dispersos, enquanto se reforça uma estreita cooperação entre cada grupo e o seu Meio: não importa 


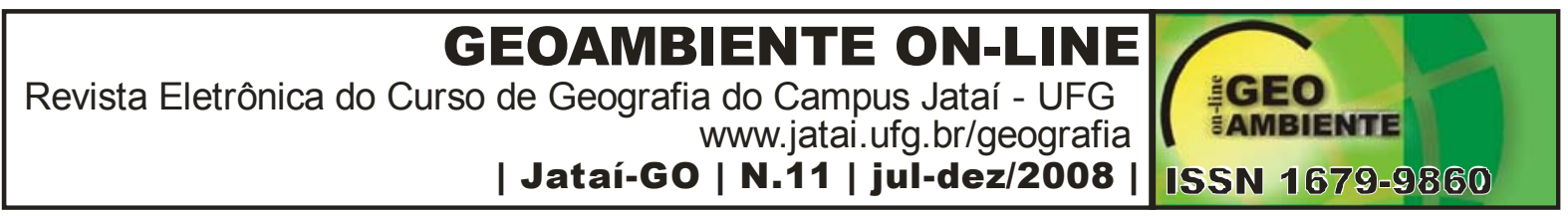

que as trevas, o trovão, as matas, as enchentes possam criar o medo: é o tempo do homem amigo e da natureza amiga (grifo do autor) (SANTOS, 1992, p. 4).

O primeiro conceito ocidental filosófico de natureza, formulado na cosmologia grega com os pré-socráticos, rompe com a tradição mítica, mas mantém a idéia de interação homem-natureza.

Para o pensador pré-socrático, a visão de natureza está relacionada a physis, que indica a gênese de todas as coisas.

Pensando a physis, este filósofo (...) pensa o ser e a partir da physis pode então chegar a uma compreensão da totalidade do real: do cosmos, dos deuses e das coisas particulares, do homem e da verdade, do movimento e da mudança, do animado e do inanimado, do comportamento humano e da sabedoria, da política e da justiça (GONÇALVES, 1996, p. 31).

Com Platão e Aristóteles já começa a se impor um certo privilégio do homem sobre a natureza. O conceito de physis vai sendo modificado, perdendo a idéia de gênese e orientando-se no âmbito metafísico: agora a natureza não se explica por si mesma, passando a ser concebida de modo teleológico, para um fim além de si mesma.

O entrelaçamento das visões de natureza pré-socrática e aristotélico-platônica a partir da segunda metade do século XIX, época na qual tornam-se notórios os efeitos danosos da atuação predatória do homo faber orientado pelo industrialismo forjado no seio da acumulação capitalista no período da Revolução Industrial, leva à construção da concepção romântica de natureza que, por sua vez dá suporte à vertente ambientalista do preservacionismo contrária ao antropocentrismo moderno e ao teocentrismo medieval (MELO e SOUZA, 2007).

A ideologia biocêntrica de natureza é retomada na segunda metade do século XX com a perspectiva ambientalista denominada Ecologia Profunda, que enxergava uma existência igualitária para todos os seres, sem o homem no topo hierárquico.

A assimilação dos pensamentos aristotélico-platônicos que o cristianismo fará na Idade Média leva à separação entre espírito e matéria, servindo de base para a recente concepção de ambientalismo tecnocentrista.

Foi na Idade Média, por exemplo, que teve início a prática de dissecação de cadáveres no Ocidente europeu. Esse fato é de uma importância muito grande e se constitui numa decorrência lógica 


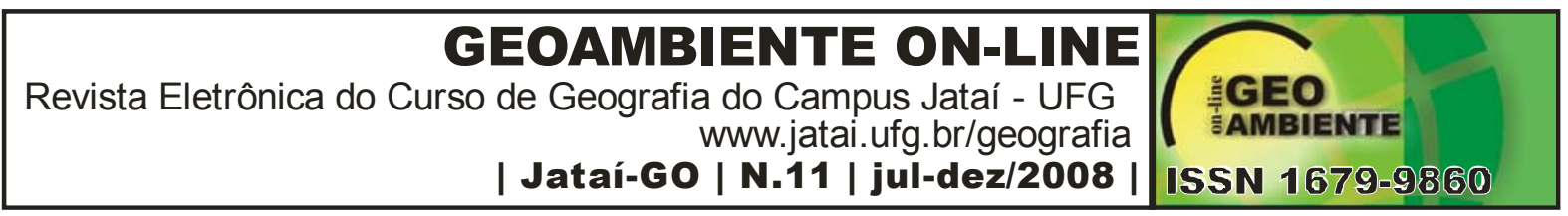

de uma Filosofia que separa corpo e alma. Se a alma não habita mais o corpo depois de morto, este, como objeto, pode ser dissecado anatomicamente. Afinal, aquilo que anima (do grego ânima, alma) não está mais presente (GONÇALVES, 1996, p. 32).

As práticas de dissecação de cadáveres do período feudal são o passo inicial para a formulação de uma filosofia racional-pragmática que irá despontar na Idade Moderna. Assim, à natureza delegava-se o mesmo caminho do cadáver, em que sua dissecação era condição de tornar-se o mais racional possível. "Um mundo desnaturalizado e uma natureza desumanizada, eis o ponto de partida do pensamento/sentimento/ação do mundo moderno" (GONÇALVES, 1996, p. 27).

No contexto da Modernidade, a ciência se afirma como via oficial de compreensão do mundo, agora essencialmente humano, antropocêntrico. Os princípios fundamentais que guiarão a reflexão neste período são encontrados no pensamento de René Descartes, precursor de uma filosofia racionalista que concebe a natureza como "um sistema de leis matemáticas estabelecidas por um Deus racional” (GOMES, 1996, p. 71).

Para Descartes a ordem natural é inteligível e acessível ao ser humano, sendo possível a este conhecer a força e a ação dos corpos que os cerca: fogo, água, ar, astros, céus para poder empregá-los da mesma maneira em todos os usos para os quais são próprios e assim se tornar como que senhor e possuidor da natureza (DESCARTES, s/d apud GONÇALVES, 1996, p. 33). Esta concepção cartesiana de natureza como algo externo (res extensa) promove a ruptura homem-natureza, espírito-matéria, sujeito-objeto que está alinhada a um conjunto de idéias dentre as quais se inserem os modelos newtoniano e baconiano em que a natureza passa a ser desenhada como algo racionalizável/racionalizado.

Qualquer que seja o julgamento a propósito do modelo mais importante da época, de Bacon, de Galileu, de Descartes ou de Newton, o fato é que uma nova concepção da natureza, inteligível pelo esforço de uma observação atenta e racional, começa a se desenhar (GOMES, 1996, p. 74).

Na visão de Melo e Souza (2007) esta concepção de natureza será o sustentáculo da corrente ideológica antropocêntrica do sentido de ambiente e conseqüentemente desta vertente do ambientalismo. Essa concepção de Natureza formulada na Modernidade enquanto positividade absoluta está no bojo das formulações ideológicas dos ambientalistas de orientação antropocentrista. (...) É exatamente a possibilidade do homem atuar sobre a natureza, enquanto operador independente 


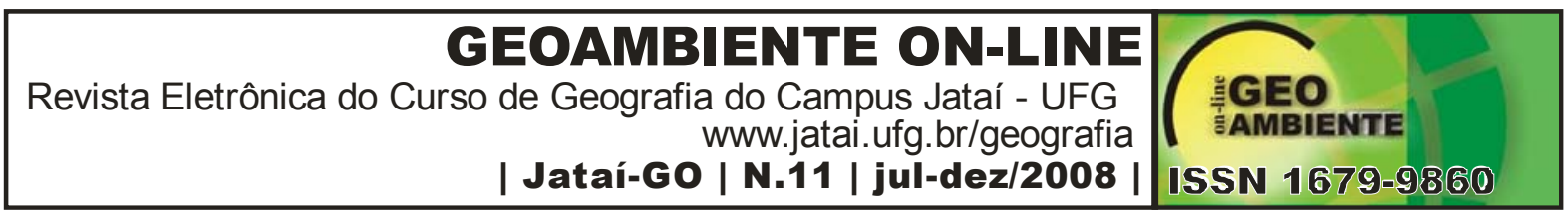

de qualquer sensitividade e envolvimento, que alicerça os argumentos daqueles mais identificados com a postura ideológica antropocentrista do ambientalismo (MELO e SOUZA, 2007).

O desprendimento dos vínculos de amizade com a natureza e o surgimento do aufklärung, ou seja, do sujeito iluminado pela luz da razão, marcou um contexto de potencialização da técnica, da capacidade de esquadrinhar o mundo e extrair da "natureza externalizada" aqueles elementos necessários à acumulação de riquezas.

Esta relação entre o caráter filosófico do iluminismo e o desenvolvimento industrial que representou uma notável mutação da técnica - demonstra a íntima relação da Revolução Francesa com a Revolução Industrial.

Nesse contexto, na moderna sociedade industrial a natureza é cada vez mais tecnosfera; a relação entre o homem e o ambiente que está em seu entorno é cada vez mais instrumentalizada. Para isso, são destruídas outras relações sócio-culturais com o ar, a água, com a flora, a fauna, enfim, com o universo (GONÇALVES, 1996).

A concepção de natureza externalizada se desenvolve nas mais variadas nuanças. Nesse sentido é que Kant (apud MELO e SOUZA, 2007) passa a enxergá-la a partir de uma concepção humanista, remetendo o juízo da natureza somente à percepção humana.

Quanto a esse empreendimento racional realizado por Kant (apud MELO E SOUZA, 2007) resgata o pensamento de R. Blackburry (2000, apud MELO e SOUZA, 2007) afirmando que na visão kantiana enraíza-se uma ideologia do capitalismo ecológico ou green capitalism, relacionada a uma das vertentes do ambientalismo que preconiza uma relação de acomodação das exigências do meio ambiente frente aos avanços tecnológicos, no tocante a contornar e mesmo resolver problemas ambientais sem transformar as bases da acumulação do regime capitalista em escala local e planetária.

A idéia de natureza externalizada se caracterizou como forma de natureza hostil (SANTOS, 1992), que tinha como função legitimar o ataque do homem ao meio ambiente. Desta forma,

(...) a natureza como objeto de trabalho, assim como os instrumentos de trabalho que compõem os meios de produção são privatizados, ou seja, pertencem aos detentores do capital, o que implica diretamente no antagonismo de classes (GOMES, 1996) 


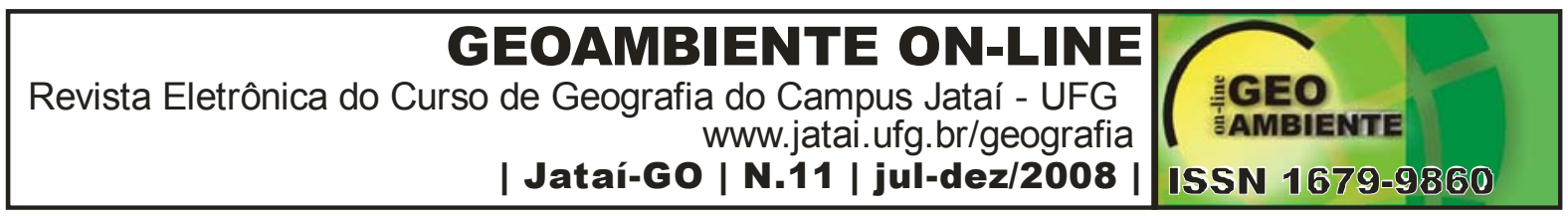

Portanto, a natureza que antes da história do homem era una, continua a sê-lo, em si mesma, apesar das partições que o uso do planeta pelos homens lhe infligiu. Agora, porém, há uma enorme mudança. Una, mas socialmente fragmentada, durante tantos séculos, a natureza é agora unificada pela História, em benefício de firmas, estados e classes hegemônicas (grifos do autor) (SANTOS, 1992, p. 6).

Contrapondo-se a esta concepção de natureza externalizada, Karl Marx compreende a natureza como unificada ou não externalizada. Marx procura explicar através do materialismo dialético a interdependência entre natureza e sociedade, de outra forma, a natureza passa a ser entendida como produto social para os teóricos marxistas, somente além dos domínios do modo de produção capitalista poderão ser engendradas as condições de um relacionamento mais harmônico e menos predatório com o mundo natural, a fim de suplantar a barbárie perpetrada pelo capital sobre a humanidade com base em outro padrão de uso e distribuição dos recursos ambientais, que tenha como princípio o respeito aos limites de renovação da natureza (MELO e SOUZA, 2007).

Ainda opondo-se à idéia de natureza exterior, esboçada no seio da Modernidade, encontra-se a concepção romântica de natureza delineada por Schelling. Este teórico retoma a concepção dos filósofos pré-socráticos ao entender que a natureza é "uma força viva, o princípio e a finalidade de todas as coisas, em suma, a totalidade" (GOMES, 1996, p. 97).

As idéias de Schelling (apud GOMES, 1996) receberam a denominação de Filosofia da Natureza e serviram de base ideológica à formulação, ao longo do século XIX, da postura do ambientalismo conhecida como holística.

Nesta perspectiva filosófica ainda merecem destaque, pelas repercussões no campo ambiental, a fenomenologia e a hermenêutica que, assim como a Filosofia da Natureza entendiam a natureza como uma totalidade.

Assim, ao dar sustentáculo a novas formas de pensar o meio ambiente, estas concepções filosóficas buscaram (...) erigir uma nova tessitura complexa e multifacetada que possibilite avançar rumo à superação da crise da racionalidade cientificista, erigida no bojo da modernidade, cujo corolário atual consiste na adoção da sustentabilidade (MELO e SOUZA, 2007, p. 57). 


\begin{tabular}{|c|c|}
\hline $\begin{array}{r}\text { GEOAMBIENTE ON-LINE } \\
\text { Revista Eletrônica do Curso de Geografia do Campus Jataí - UFG } \\
\text { www.jatai.ufg.br/geografia } \\
\text { | Jataí-Go | N.11 | jul-dez/2008 | }\end{array}$ & $\begin{array}{l}\text { TGEO } \\
\text { ISAMBIENTE } \\
\text { ISSN } 1679-9860\end{array}$ \\
\hline
\end{tabular}

IV - Desdobramentos interpretativos dos trânsitos epistêmicos no campo ambiental no Brasil

Nesse decurso das concepções de natureza ficam nítidas que estas orientaram as formulações das mais variadas vertentes ideológicas do campo ambiental, ao longo do século $\mathrm{XX}$, com reflexos até os dias atuais.

Assim a relação sociedade-natureza, fruto das visões de natureza construídas ao longo dos séculos, norteou os discursos das variadas ideologias ambientalistas responsáveis pelas orientações teóricas que nutriram as diversas formas de apropriação da natureza por vários segmentos sociais.

Esta relação entre ideologia e apropriação da natureza já se faz notar desde o século XVII, pelo surgimento de parques e jardins em cidades da Alemanha e Inglaterra. A adoção destas áreas verdes remonta à idéia de usufruto da vida natural e repouso evocada por Schelling (apud GOMES, 1996).

A visão romântica de natureza se fez presente no Brasil, a exemplo e sob influência dos países europeus, com a construção do Jardim Botânico do Rio de Janeiro. Tal aspecto é bastante enfatizado por Needel ao discutir as razões de uma bèlle époque brasileira. No entanto, os primórdios desta vertente preservacionista do ambientalismo no Brasil, podem aludir à atuação de naturalistas e artistas anglo-saxônicos como Franz Post e Varnhagem no país ou até mesmo à Carta de Caminha quando do descobrimento do Brasil (BUENO, 2001 apud MELO e SOUZA, 2007).

As mais notáveis práticas ambientalistas, surgidas a partir do século XIX, estiveram vinculadas às ideologias cornucopiana e tecnocentrista decorrentes do desenvolvimento da Revolução Industrial e da difusão das idéias liberais que culminaram no modelo capitalista de produção.

No Brasil, as idéias de natureza enquanto fonte inesgotável de recursos à disposição do homem como prega o ambientalismo cornucopiano, pode ser bem visualizado no período da ditadura militar, quando o Brasil alcança o maior nível de desenvolvimento econômico de sua história.

As práticas desenvolvimentistas desta época iam totalmente de encontro à conservação dos recursos naturais. Nas palavras de Gonçalves (1996, p. 14) "Esse desenvolvimento se 


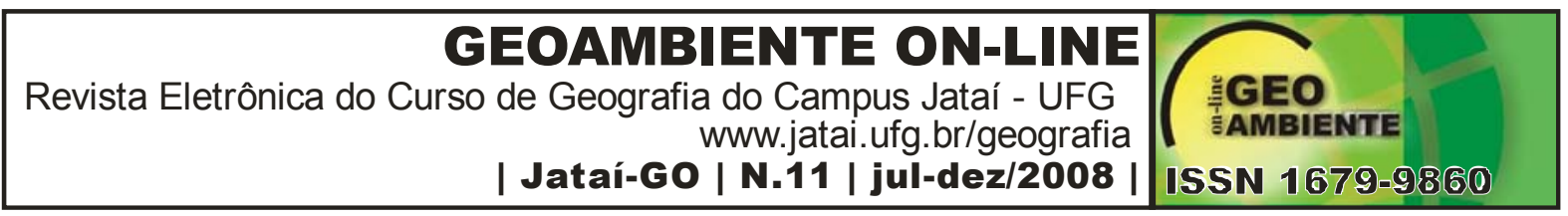

fazia ainda num país onde as elites dominantes não tinham por tradição respeito seja pela natureza, seja pelos que trabalham". Sobre as práticas agrícolas daquele momento o autor ainda afirma que quanto ao latifúndio, bastava o desmatamento e a ampliação da área cultivada para se obter o aumento da produção e isto nos levou a uma tradição de pouco respeito pela conservação dos recursos naturais, a não ser nas letras dos hinos e nos símbolos nacionais (GONÇALVES, 1996, p.15).

A doação de imensas extensões de terras pelo governo militar a grandes empresas nacionais e transnacionais faz aumentar ainda mais os problemas ambientais brasileiros, principalmente na região Amazônica.

Para GOMES (1996, p. 12) tais (...) problemas foram sentidos ou agravados com aberturas de estradas, como a Transamazônica, além da implantação, sem qualquer planejamento dos denominados núcleos de colonização. O conhecimento da região levou a várias práticas predatórias como o garimpo, que contribuíram para a sujeição e massacre dos próprios índios.

No início da década de 1970 passa a vigorar com maior intensidade a vertente ambientalista pautada no conservacionismo. Emergida no bojo da crise do modelo capitalista de produção, a perspectiva conservacionista busca "estabelecer, no mínimo, limitações mais nítidas ao uso desenfreado das inovações tecnológicas, sob pena de comprometimento da qualidade da vida em termos imediatos e sua inviabilização para futuras gerações" (MELO e SOUZA, 2007). Nesse ínterim é que se configura a Primeira Conferência sobre Meio Ambiente e Desenvolvimento e conseqüentemente, os pilares para o estabelecimento do desenvolvimento sustentável, que irá permear as discussões acerca da problemática ambiental a nível planetário nas décadas subseqüentes.

No Brasil, a ótica conservacionista orientou os primórdios das discussões sobre medidas de proteção à biodiversidade, na busca de integrar a conservação do meio ambiente às necessidades de desenvolvimento nacional (CÂMARA, 1998 apud MELO e SOUZA, 2007).

Ainda no período de ditadura militar, se estabelece o movimento ambientalista brasileiro orientado pelo viés preservacionista dos movimentos de contracultura dos anos sessenta a exemplo dos beatinik e dos hippies, além da atuação de pacifistas políticos nos Estados Unidos e Europa contra a verdadeira chacina cometida no Vietnã primeiro pelo governo francês e depois pelo estadunidense (GONÇALVES, 1996). 


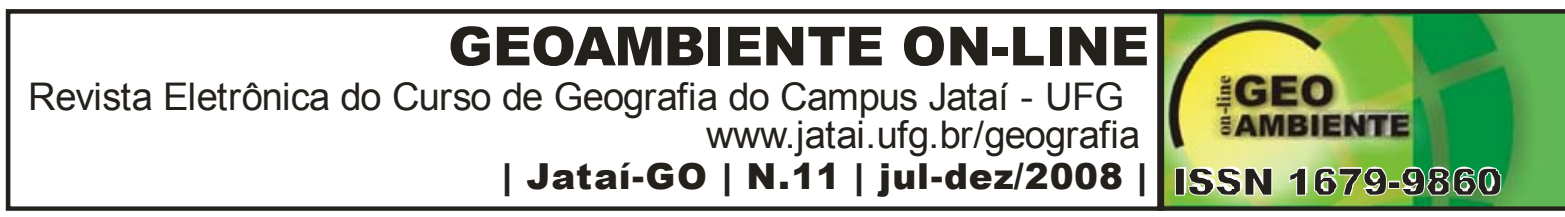

Com o processo de abertura política brasileira, nos anos 1980, surge um ambientalismo ou ecologismo como dito por Waldman (1992), que se distancia do preservacionismo, estando mais ligado às questões sociais.

(...) Enquanto manifestação de demandas sociais profundas, o ecologismo insere-se em acentuado debate político, pois é neste debate que também se inserem as problemáticas ambientais.

No caso brasileiro, é clara a necessidade de discutir suas perspectivas políticas. Particularmente, o fato de o ecologismo brasileiro atuar numa realidade que conjuga a depredação de uma sociedade "industrial avançada" com mazelas sociais típicas do Terceiro ou de "Quarto" Mundo, coloca para ele um duplo desafio: discutir tanto a questão ambiental propriamente dita quanto a questão social mais ampla, perspectiva que orientaria aproximação com os diferentes segmentos do movimento popular (WALDMAN, 1992, p. 27).

Na década de 1990, ao sediar a Segunda CNUMAD, o Brasil marca de vez sua participação no cenário ambiental internacional. No Fórum Mundial de ONG's, paralelo à Rio-92, uma rede de grupos ambientalistas brasileiros obtém maior visibilidade ao introduzir uma discussão ambiental pautada na adoção de estilos alternativos de vida menos degradantes, na redução dos níveis de consumo, no estabelecimento de princípios éticos rumo à produção e consumo sustentáveis. Tais ideais remetem ao pensamento holístico ainda que nem sempre estes grupos ambientalistas tenham definições de suas lutas e demandas a partir de uma clara compreensão de suas inspirações teóricas (MELO e SOUZA, 2007).

Após-ECO-92, a temática da relação homem-natureza passou a ser mais susceptível ao jogo ideológico que, fazendo-a transitar entre os diversos ambientalismos, tornou a questão ambiental mais do que nunca uma questão de território e poder, já que ela passa a ser apropriada com maior intensidade pelos diversos segmentos sociais, entre eles a mídia.

Mendonça (1994) afirma que é freqüente encontrar entre os meios de comunicação, uma abordagem voltada à questão ambiental, embora na maioria das vezes esta esteja deslocada da noção científica de meio ambiente. Santos (1992, p. 8) numa análise mais incisiva expõe:

A mediação interessada, tantas vezes interesseira, da mídia, conduz, não raro, à doutorização da linguagem, necessária para ampliar o seu crédito, e à falsidade do discurso, destinado a ensombrear o entendimento. $\mathrm{O}$ discurso do meio ambiente é carregado dessas tintas, exagerando certos aspectos em detrimento de outros. 


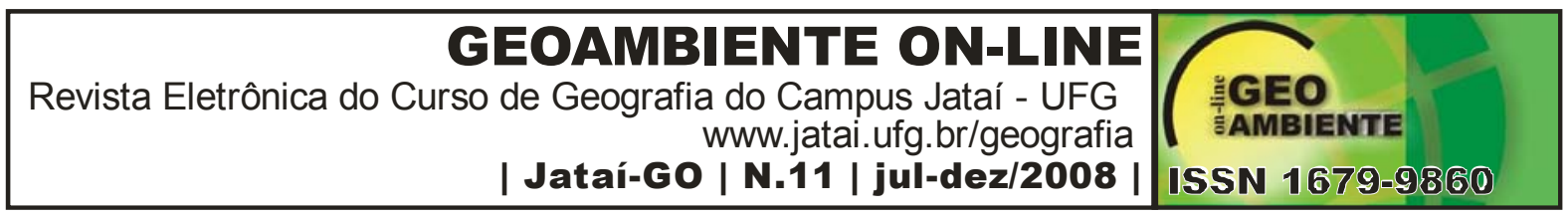

A mídia, ao que parece, não incorpora um sentido unívoco nem unificador do ambiental. Em alguns casos ela vincula tal questão ao antropocentrismo, ao tratar de fenômenos naturais como causador de grandes malefícios à sociedade, quando o que está em jogo, de fato, são os conflitos de apropriação e uso do ambiente travado entre atores sociais de níveis e tipos de poder distintos. Em outros momentos estas matérias lamentam possíveis prejuízos estéticos da paisagem causados pela "mão destruidora" do "homem", orientadas por um sentido biocentrista do ambiente. Em outros ainda, numa visão tecnocentrista, comemoram a vitória do homem sobre a hostilidade da natureza a partir da técnica, como uma regulação racional, uma vitória dita não prejudicial ao ambiente.

\section{V - Para concluir... por ora: Gaia como hermenêutica instauradora de novo(s) sentido(s) de ambiente}

Com a Hipótese Gaia formulada no fim dos anos setenta por James LOVELOCK, retoma-se a concepção aristotélica de inter-relação inerente ao mundo natural, posto que GAIA nada mais é do que uma concepção da Terra e dos seus seres como um organismo autoconsciente e interligado e autodeterminado.

A concepção de GAIA é desenvolvida ainda alimentada pelo ideal de natureza em Aristóteles - mas não somente - na segunda metade do século XIX pelos naturalistas alemães e flamengos, sobretudo podendo ser destacada em Alexander von Humboldt o qual afirma que “tudo está interligado".

Assim, a espiral se completa tem-se, no espectro das idéias que cimentam as concepções dos distintos matrizes do campo ambiental transitam entre a contribuição destes filósofos matriciais para a definição, na contemporaneidade, das orientações discursivas orientadas pela complexidade das aspirações dos vários sentidos do ambiental e as suas correlatas práticas das vertentes dos ambiental(ismos), e, ao sabor dos poderes que a sustentam torna esta temática mais difusa, por que multifocalizada ou esfacelada das concepções de ambiente divorciadas das do sentido matricial de natureza.

Neste contexto, as práticas sócio-educativas podem reinterpretar suas formulações considerando aspectos como a postura e a prática da inclusão, do caráter transcendente ao humano da natureza e da necessidade de reintegração do sentido de ambiental a partir de uma 


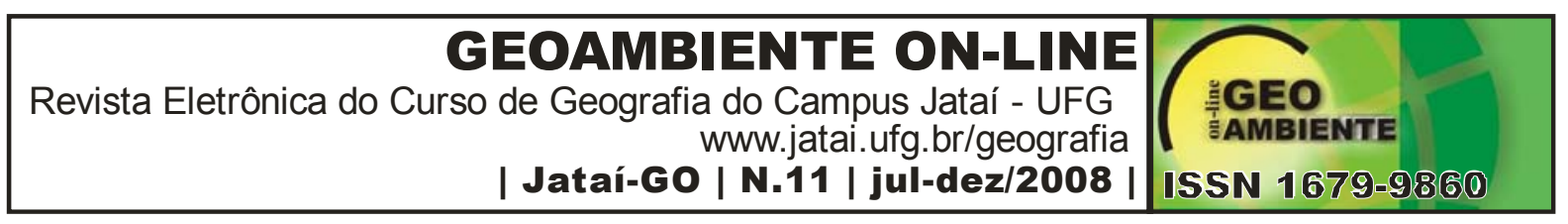

compreensão sócio-política da relação sociedade-natureza, posto todo problema ambiental ser natural e social de modo indissociável.

\section{VI - Referências Bibliográficas}

CARVALHO, Isabel Cristina Moura de. "Os sentidos de ambiental: a pedagogia da complexidade". In: LEFF, Enrique (org.). A Complexidade Ambiental. São Paulo, Cortez Editora, pp. 99-120. 2003.

FLORIANI, Dimas. "Ciências em Trânsito, Objetos Complexos: Práticas e Discursos Ambientais". In: Revista Ambiente e Sociedade, vol. IX, n. 1, ISSN 14-753X. pp. 65-80. 2006,

GOMES, Paulo da Costa. Geografia e Modernidade. Rio de Janeiro, Bertrand Brasil, 1996.

GONÇALVES, Carlos Walter Porto. (Des) caminhos do Meio Ambiente. Campinas, Papirus, 1996.

MELO e SOUZA, Rosemeri. Redes de Monitoramento e Tramas da Sustentabilidade Scioambiental. São Paulo, Annablume, 2007.

MENDONÇA, Francisco. Geografia e Meio Ambiente. São Paulo, Contexto, 1994.

SANTOS, Milton. A redescoberta da natureza. São Paulo, AGB, mimeo. 1992

SERRES, Michel. O Contrato Natural. Lisboa, Edições Piaget, 1990.

WALDMAN, M. Ecologia e Lutas Sociais no Brasil. São Paulo, Contexto, 1992. 